\title{
CARACTERIZAÇÃO FÍSICA E QUÍMICA DA BIOMASSA USADA COMO COMBUSTÍVEL SÓLIDO EM UMA CALDEIRA
}

\author{
Natália R. de Carvalhoa, João L. de Barros ${ }^{\mathrm{b}}$, Diego A. da Silva ${ }^{\mathrm{a}}$, Gabriela T. Nakashima e Fábio M. Yamaji ${ }^{\mathrm{a}, *,(1)}$ \\ aDepartamento de Ciências Ambientais, Universidade Federal de São Carlos, 18052-780 Sorocaba - SP, Brasil \\ 'Instituto Federal de Educação, Ciência e Tecnologia de São Paulo, 18095-410 Sorocaba - SP, Brasil
}

Recebido em 02/06/2020; aceito em 29/09/2020; publicado na web em 04/11/2020

\begin{abstract}
PHYSICAL AND CHEMICAL CHARACTERIZATION OF BIOMASS USED AS SOLID FUEL IN A BOILER. Biomass is a renewable energy source most used in the world, however, depending on the chemical properties and origin of the material used as biofuel, the amount of ash generated during combustion can be high, harming the energetic harnessing. The objective of this study was to characterize chemically and physically biomass: bark, sawdust, and urban pruning; used for energy generation. Also, part of the study was the physical characterization of briquettes produced from these materials. The analyzes performed to characterize the biomass were: moisture determination, higher heating value, proximate analysis and chemical composition - extractives, lignin and holocellulose contents. Subsequently, the biomass was briquetted and the mechanical properties of the briquettes were tested. The results showed that all biomass (bark, sawdust, and urban pruning) has the energy potential to be used in the industry. T1 briquettes (100\% bark) showed the highest mechanical resistance. However, the formation of blends should be sought to minimize the ash content in the boiler. Thus, blends T2 and T3 can be considered as the best alternatives for the company.
\end{abstract}

Keywords: bioenergy; eucalyptus; briquettes; ash; thermogravimetry.

\section{INTRODUÇÃO}

A preocupação com as mudanças climáticas e as limitações nas fontes de energia fósseis fez o mercado global de bioenergia crescer nas últimas décadas, ${ }^{1,2}$ tornando-se crucial a criação de sistemas de energias sustentáveis para garantir o bem-estar humano. ${ }^{3}$

A bioenergia é considerada uma das energias mais atrativas por oferecer alternativa sustentável para resíduos diversos, utilizando-se a biomassa como combustível sólido e apresentando baixas emissões de $\mathrm{CO}_{2}{ }^{4,5}$ Nas últimas décadas, também tem sido estudada a conversão termoquímica da biomassa, visando a melhoria de suas propriedades térmicas. ${ }^{6,7}$

Dependendo das características e da procedência, a quantidade de cinzas gerada pode ser elevada, causando desgaste dos equipamentos e aumentando o custo de manutenção. ${ }^{8} \mathrm{Uma}$ alternativa seria trabalhar com biomassas com características determinadas, como baixo teor de cinzas. No entanto, esse tipo de biomassa possui um preço maior, elevando os custos com energia. Outra opção seria trabalhar com blendas de biomassa, buscando composições para diminuir a variação dos conteúdos de umidade e teores de cinzas. ${ }^{9} \mathrm{O}$ ideal seria misturar esses materiais antes de inserir na caldeira.

Em geral, a biomassa in natura apresenta uma umidade considerada alta (>30\%) para uso como combustível. ${ }^{10,11}$ Outro agravante é a baixa densidade a granel $\left(<0,25 \mathrm{~g} \mathrm{~cm}^{-3}\right)$ de alguns tipos de biomassa como gramíneas, serragem e casca entre outras, que dificulta o transporte, estoque e manuseio do material. ${ }^{12}$

Embora a biomassa seja um material abundante, é utilizado de forma não otimizada como combustível sólido. As características como heterogenidade, baixa densidade, alto teor de cinzas, umidade elevada da biomassa requerem estudos para que o material seja utilizado com maior eficiência. Uma forma de contornar esses problemas é pela compactação dessa biomassa na forma de briquetes ou pellets. A produção de briquetes/pellets exige uma umidade controlada (10-12\%) e resulta num produto homogêneo, com maior densidade $\left(0,7-1,1 \mathrm{~g} \mathrm{~cm}^{-3}\right)$ e de melhor qualidade.

O objetivo deste trabalho foi caracterizar química e fisicamente a biomassa utilizada como combustível sólido em uma caldeira de uma indústria de painéis. Como objetivos específicos: utilização da biomassa na produção de briquetes e caracterização dos briquetes.

\section{PARTE EXPERIMENTAL}

Os materiais (biomassas) foram coletadas no pátio de uma indústria de painéis da cidade de Salto/SP. Foram coletados três tipos de materiais: resíduos da poda urbana (mistura de espécies), casca e serragem de madeira oriundas do híbrido Eucalyptus urophylla x Eucalyptus grandis, popularmente conhecido como urograndis. Para a produção de painéis é feito o descascamento das toras no pátio da indústria. A casca representa aproximadamente $6 \%$ do volume das toras. Como resultado dessa operação, a casca é o resíduo mais abundante. A serragem é um resíduo do processo industrial (corte dos painéis) e representa o menor volume. O material da poda urbana é composto por galhos, folhas e tocos de diversas espécies (usadas na arborização urbana) que são recolhidos até o pátio da indústria, onde são triturados e destinados à caldeira. Para realizar as análises os materiais passaram por um processo de moagem, em moinho tipo Willey MA-340, e peneriamento para obtenção de partículas com tamanho adequado às normas.

\section{Determinação de umidade}

A umidade foi obtida, pela diferença da massa inicial (umidade na condição em que foi coletada) e massa seca. Utilizou-se $1 \mathrm{~g}$ de material que foi submetido à secagem, em estufa, na temperatura de $105 \pm 2{ }^{\circ} \mathrm{C}$, até a estabilização do peso da amostra. ${ }^{13} \mathrm{~A}$ umidade foi calculada de acordo com a equação 1 :

$$
\mathrm{U}=(\mathrm{Pu}-\mathrm{Ps}) \div \mathrm{Ps} \times 100
$$

onde: U: umidade (\%); Pu: peso úmido (g); Ps: peso seco (g). 


\section{ANÁLISE IMEDIATA}

A análise imediata foi realizada em mufla. Para o teor de voláteis utilizou-se $1 \mathrm{~g}$ de material (seco). O cadinho foi colocado na mufla à $950{ }^{\circ} \mathrm{C}$ por 7 min. ${ }^{14} \mathrm{O}$ cálculo dos teores de voláteis foi feito de acordo com a equação 2 :

$$
\mathrm{TV}=(\mathrm{mi}-\mathrm{mf}) \div \mathrm{mi} \times 100
$$

sendo: TV: teor de voláteis (\%); mi: massa inicial (g); mf: massa final $(\mathrm{g})$.

Para determinação do teor de cinzas utilizou-se $1 \mathrm{~g}$ de material (seco). $\mathrm{O}$ cadinho foi colocado na mufla à $600^{\circ} \mathrm{C}$ por $4 \mathrm{~h}$ (até peso constante). ${ }^{14} \mathrm{O}$ cálculo dos teores de cinzas foi realizado de acordo com a equação 3 :

$$
\mathrm{TC}=(\mathrm{m} 2-\mathrm{m} 1) \div \mathrm{m} \times 100
$$

sendo: TC: teor de cinzas (\%); m: massa da amostra isenta de umidade (g); m1: massa do cadinho (g); m2: massa do cadinho mais o resíduo após período em mufla $(\mathrm{g})$.

O teor de carbono fixo (TCF) foi obtido de acordo com a Equação 4:

$$
\mathrm{TCF}=100-(\mathrm{TV}+\mathrm{TC})
$$

sendo: TCF: teor de carbono fixo (\%); TC: teor de cinzas (\%); TV: teor de voláteis $(\%)$.

\section{Poder calorífico superior (PCS)}

O processo de determinação do PCS foi realizado em um calorímetro IKA C200, sendo 2 repetições para cada material. ${ }^{15}$

\section{Caracterização química}

A preparação da biomassa para análise química foi feita baseada na norma TAPPI $264 \mathrm{~cm}-97 .{ }^{16,17}$ A análise química foi composta por: teor de extrativos (extraídos via Soxhlet: ciclohexano/ etanol, etanol e água quente) $;{ }^{18}$ teor de lignina Klason; ${ }^{19}$ e teor de holocelulose.

\section{Análise Termogravimétrica (TGA)}

Foi realizada em Analisador Termogravimétrico Pyris 1 TGA (Perkin Elmer), na faixa de temperatura ambiente $\left(25^{\circ} \mathrm{C}\right)$ até $700{ }^{\circ} \mathrm{C}$ e taxa de aquecimento de $10{ }^{\circ} \mathrm{C} \mathrm{min}^{-1}$, fluxo de gás (oxigênio) $20 \mathrm{~mL} \mathrm{~min}^{-1}$, com cadinho de platina. ${ }^{6,20,21,22}$

\section{Compactação da biomassa}

A produção de briquetes foi realizada em uma prensa hidráulica. Os briquetes foram produzidos em molde cilíndrico de aço inoxidável, com $35 \mathrm{~mm}$ de diâmetro interno. O material foi prensado a 12 toneladas e tempo de retenção da pressão de 30 segundos. ${ }^{23} \mathrm{~A}$ prensagem foi feita sem uso de aquecimento e sem aglutinante. A produção dos briquetes teve como foco o aproveitamento da casca (material mais abundante na fábrica). Os tratamentos foram definidos para responder às dúvidas: é possível produzir briquetes só com a casca? A formação de blendas melhora as propriedades dos briquetes? Os tratamentos foram: T1 (100\% casca); T2 (50\% casca $+50 \%$ poda); $\mathrm{T} 3(50 \%$ casca $+25 \%$ poda $+25 \%$ serragem $)$.

\section{Estabilidade dimensional dos briquetes}

Com auxílio de paquímetro digital, mediu-se as dimensões de 10 amostras por tratamento e averiguou-se a expansão volumétrica dos briquetes ao longo de $48 \mathrm{~h}$, sendo as medições realizadas em: $1,4,12,24$ e 48 h após briquetagem, para observar a estabilidade dimensional do material. ${ }^{24} \mathrm{O}$ acondicionamento dos briquetes foi ao ar livre, na bancada do laboratório com temperatura entre $20-25{ }^{\circ} \mathrm{C}$ e umidade relativa 50-70\%. Para o cálculo da expansão volumétrica final dos briquetes, utilizou-se a equação 5 :

$$
\text { Expansão volumétrica final }(\%)=(\mathrm{Vf}-\mathrm{Vi}) \times 100 \div \mathrm{Vi}
$$

sendo: Vi: volume inicial dos briquetes - logo após briquetagem $\left(\mathrm{mm}^{3}\right)$; Vf: volume final dos briquetes - 48 horas após briquetagem $\left(\mathrm{mm}^{3}\right)$.

\section{Resistência mecânica}

Destinou-se 10 briquetes para ensaios estáticos e 4 para ensaios dinâmicos. Os ensaios de resistência mecânica estáticos de tração por compressão diametral foram realizados na máquina universal de ensaios EMIC DL 30000 N..$^{25}$

Também, foram realizados ensaios mecânicos dinâmicos de friabilidade, conhecidos popularmente como teste de tamboramento, submetendo 2 briquetes por vez, em friabilômetro de dimensões 400x400x $100 \mathrm{~mm}$ e com rotação de $35 \mathrm{rpm}$ por 15 minutos. ${ }^{26}$ Para o cálculo da resiliência utilizou-se a equação 6 :

$$
\text { Resistência }(\%)=(\mathrm{mi} \div \mathrm{mf}) \times 100
$$

sendo: mi: massa inicial (g); mf: massa retida na peneira após ensaio $(\mathrm{g})$.

\section{Análise estatística}

Realizou-se Análise de Variância (ANOVA) para um fator, seguido de Teste Tukey para comparações de média, com o auxílio do software R Core Team, ${ }^{27}$ com significância de 0,05 . Previamente os dados passaram pelo teste de homogeneidade Bartlett e teste de normalidade de Shapiro-Wilk.

\section{RESULTADOS E DISCUSSÃO}

\section{Determinação de umidade}

Os materiais, nas condições em que se encontravam no pátio da indústria, apresentaram as seguintes umidades na base seca: Casca $-97 \%$, Poda $-60 \%$ e Serragem $-8 \%$. Na indústria, para a produção de energia, a umidade é uma das variáveis mais importantes, sendo ideal que os materiais apresentem até $35 \% .{ }^{28} \mathrm{~A}$ umidade $>15 \%$ causa perdas no aproveitamento energético, visto que o poder calorífico diminui com o aumento da umidade no material. Ainda, pode diminuir a resistência mecânica (compressão diametral) e diminuir a resistência ao tamboramento (maior índice de quebra dos briquetes). ${ }^{29,30}$ Para a produção de briquetes, as umidades de biomassa de eucalipto que proporcionam melhores propriedades mecânicas estão entre 10 e $12 \% .^{31}$

A casca e a poda urbana apresentaram umidades consideradas elevadas, devido ao sistema de armazenamento destes resíduos, que é realizado sob forma de pilhas (pequenos montes) a céu aberto. Assim, a umidade fica retida no interior das pilhas, ${ }^{28}$ dificultando a secagem natural (ao ar livre) desses materiais. A secagem forçada (estufa, 
silos) pode ser uma alternativa, mas reflete em altos custos com equipamentos e energia. A serragem, por sua vez, possuiu umidade baixa por se tratar de um resíduo proveniente de processo industrial de produção dos painéis $\left(200^{\circ} \mathrm{C}\right.$ na prensagem), ou seja, um material seco (armazenado em silos). As análises mostraram que a umidade está fora dos níveis considerado ideal e apresentou heterogeneidade entre os materiais. Como resultado, há uma perda de eficiência e uma maior dificuldade de manter a estabilidade de operação da caldeira. ${ }^{32}$ Desse modo, para prosseguir com as demais análises do trabalho, foi necessária a secagem em estufa das biomassas casca e poda urbana.

\section{Caracterização química}

A Tabela 1 apresenta os resultados do PCS e da análise imediata (voláteis, cinzas e carbono fixo) das biomassas estudadas.

O teor aproximado de cinzas encontrado para casca, poda e serragem foi de $9 \%, 3 \%$ e $1 \%$, respectivamente. O maior teor de cinzas na casca também foi encontrado por Juizo et al. ${ }^{33}$ Os autores mostraram que existe uma variação entre as espécies: $E$. deanei $(14,06 \%)$, E. viminalis $(8,05 \%)$, E. globulus $(7,47 \%)$, E. robusta $(6,44 \%)$ e $E$. grandis $(6,27 \%)$. Para a empresa, o ideal é que o teor de cinzas da caldeira seja $<4 \%$ para evitar a corrosão, desgaste ou incrustações nos equipamentos e consequentes gastos com manutenção. ${ }^{34}$ Deste modo, o valor de cinzas obtido da casca de urograndis pode ser considerado elevado para fins energéticos. De acordo com Neiva et al.,${ }^{35}$ a casca é quimicamente diferente da madeira e pode apresentar teor de cinzas cerca de sete vezes superior. Isso ocorre devido a função de proteção exercida pela casca, sendo muito rica em elementos minerais que a tornam rígida e dificultam $\mathrm{o}$ ataque por agentes patogênicos e predadores. ${ }^{33}$ Além disso, a casca pode ser facilmente contaminada pela incrustação de solo nas ranhuras do tronco, durante as fases de colheita, arraste e estocagem das toras. ${ }^{28} \mathrm{~A}$ contaminação também pode ocorrer quando a casca fica depositada sob piso não pavimentado, em contato direto com a terra, o que resulta em teores de cinzas superiores à $10 \%{ }^{28}$

Quando as biomassas apresentam valores de cinzas elevados, é recomendado a utilização em mistura com outros materiais sob forma de blendas, permitindo assim o aproveitamento de todos os resíduos e mantendo as propriedades adequadas para a queima. ${ }^{36,37}$ Desse modo, indica-se o aproveitamento da casca em conjunto com a serragem, com o objetivo de minimizar os efeitos negativos da aplicação direta da casca, tais como o alto teor de cinzas e umidade.

Outro material utilizado pela empresa é proveniente da poda urbana. O resultado do teor de cinzas $(2,89 \%)$ está dentro do limite estabelecido pela empresa $(<4 \%)$. Entretanto, o aproveitamento da poda urbana exige um acompanhamento mais constante, devido sua heterogeneidade: mistura de espécies, galhos secos/verdes, folhas, troncos com diferentes diâmetros etc. Como resultado, cada carga de poda urbana que chega no pátio da empresa apresenta carcterísticas diferentes.

Ainda, na Tabela 1, a casca apresentou os menores teores de voláteis $(76,10 \%)$ e PCS $(17.763 \mathrm{~J} \mathrm{~g}$-1), enquanto a poda $(81,83 \%$ e $\left.19.068 \mathrm{~J} \mathrm{~g}^{-1}\right)$ e a serragem $\left(81,14 \%\right.$ e $\left.19.075 \mathrm{~J} \mathrm{~g}^{-1}\right)$ não diferiram estatisticamente entre si.

Em geral o teor de voláteis das biomassa varia entre 70-85\%.38,39 O menor valor de voláteis apresentado pela casca é justificado pelo alto teor de cinzas, resultado da contaminação (areia e terra aderidas à casca). Esperava-se que a poda urbana apresentasse maior valor de voláteis pela presença de folhas. Entretanto, o material da poda também apresentou impurezas (areia e terra) que acabaram interferindo no resultado de teor de voláteis. $\mathrm{O}$ adesivo utilizado na produção dos painéis e presente na serragem não interferiu no resultado do teor de voláteis.

Normalmente, o teor de carbono fixo das biomassas varia entre $15-20 \% .{ }^{40}$ Os resultados de carbono fixo encontrados para os três materiais estão de acordo com a literatura. Isso mostra que as impurezas contidas nos materiais não comprometeram o teor de carbono fixo.

De acordo com a $\mathrm{FAO},{ }^{41}$ materiais de origem madeireira com baixos teores de cinzas e teor de umidade entre 10 e $15 \%$ apresentam poderes caloríficos entre $17000-18000 \mathrm{~J} \mathrm{~g}^{-1}$. Na Tabela 1 foram apresentados os valores de PCS (material seco). Embora teórico, o PCS permite conhecer o potencial máximo do material e fazer uma comparação entre os diversos tipos de materiais. Na prática, o poder calorífico útil poderá será menor, haja vista que a umidade dos materiais apresenta uma grande amplitude: serragem (8\%), poda $(60 \%)$ e casca $(97 \%)$.

A Tabela 2 apresenta a composição química das biomassas casca, poda e serragem.

Observa-se na Tabela 2 que a serragem obteve o maior teor de extrativos totais $(21,43 \%)$, a casca $(7,71 \%)$ e a poda $(9,5 \%)$ não diferiram estatisticamente entre si. Segundo Teixeira et al. ${ }^{42}$ os teores de extrativos das matérias-primas provenientes de resíduos de Eucalyptus sp. variam de 12 a $15 \%$. Para Moulin et al. ${ }^{43}$ os teores variaram de $2,12 \%$ a $5,64 \%$, para urograndis. O elevado teor de extrativos apresentado na serragem $(21,43 \%)$, pode ser justificado pela presença do adesivo (cola) e revestimentos melamínicos utilizados na fabricação dos painéis. A casca de eucalipto apresentou o teor

Tabela 1. PCS, teor de voláteis, cinzas e carbono fixo dos materiais casca, poda e serragem

\begin{tabular}{cccc}
\hline Características & Casca & Poda & Serragem \\
\hline PCS $\left(\mathrm{J} \mathrm{g}^{-1}\right)$ & $17.763 \pm 180 \mathrm{~b}$ & $19.069 \pm 348 \mathrm{a}$ & $19.075 \pm 106 \mathrm{a}$ \\
Voláteis (\%) & $76,10 \pm 0,08 \mathrm{~b}$ & $81,83 \pm 0,69 \mathrm{a}$ & $81,14 \pm 0,80 \mathrm{a}$ \\
Cinzas (\%) & $8,56 \pm 0,14 \mathrm{a}$ & $2,89 \pm 0,06 \mathrm{~b}$ & $0,86 \pm 0,03 \mathrm{c}$ \\
Carbono Fixo (\%) & $15,34 \pm 0,06 \mathrm{~b}$ & $15,27 \pm 0,64 \mathrm{~b}$ & $17,78 \pm 0,81 \mathrm{a}$ \\
\hline
\end{tabular}

${ }^{\mathrm{a}}$ Os valores da tabela representam as médias dos tratamento \pm desvio padrão. Letras iguais na mesma linha não diferem significativamente para teste de Tukey.

Tabela 2. Caracterização química dos materiais e teores de extrativos, lignina e holocelulose

\begin{tabular}{cccc}
\hline Análise & Casca & Poda & Serragem \\
\hline Extrativos Totais (\%) & $7,71 \pm 0,21 \mathrm{~b}$ & $9,5 \pm 0,71 \mathrm{~b}$ & $21,43 \pm 1,01 \mathrm{a}$ \\
Lignina (\%) & $16,80 \pm 1,41 \mathrm{~b}$ & $24,42 \pm 1,06 \mathrm{a}$ & $22,41 \pm 1,45 \mathrm{a}$ \\
Holocelulose (\%) & $66,85 \pm 1,60 \mathrm{a}$ & $63,19 \pm 1,75 \mathrm{~b}$ & $55,30 \pm 0,54 \mathrm{c}$ \\
\hline
\end{tabular}

${ }^{a}$ Os valores da tabela representam as médias dos tratamento \pm desvio padrão. Letras iguais na mesma linha não diferem significativamente para teste de Tukey. 
de lignina de $16,8 \%$, sendo estatisticamente menor do que o obtido para a serragem $(24,42 \%)$ e a poda urbana $(22,41 \%)$. De acordo com Neiva et al. ${ }^{35}$ a casca apresenta teor de lignina inferior ao da madeira, explicando a diferença entre os resultados encontrados para a casca e a serragem de madeira. No presente estudo, os valores de lignina encontrados para casca e a serragem aproximaram-se aos da literatura para resíduos provenientes de urograndis. O teor de lignina encontrado por Xiao et al.$^{44}$ foi de 15,6\% para casca. Morais et al. ${ }^{45}$ obtiveram $23,25 \%$ de lignina para serragem. Os teores de holocelulose das biomassas casca $(66,85 \%)$, poda $(63,19 \%)$ e serragem $(55,30 \%)$ foram inferiores aos encontrados na literatura: poda de laranjeira $(73,20 \%),{ }^{46}$ casca de urograndis $(74,81 \%)^{47}$ e serragem de urograndis $(86,25 \%) .{ }^{45}$ Os valores encontrados para a holeocelulose é resultado da heterogeneidade dos materiais: casca (impurezas, principalmente sílica), poda (diversas espécies e diferentes partes, incluindo folhas) e serragem (presença de adesivo, revestimento dos painéis). Essas impurezas (sílica, folhas, adesivo, revestimentos) iterferem nas análises de lignina e extrativos.

\section{Análise Termogravimétrica (TGA)}

A Figura 1 evidencia as curvas termogravimétricas (TG) e as derivadas das curvas termogravimétricas (DTG), em função da temperatura das biomassas casca de eucalipto, poda urbana e serragem, respectivamente.

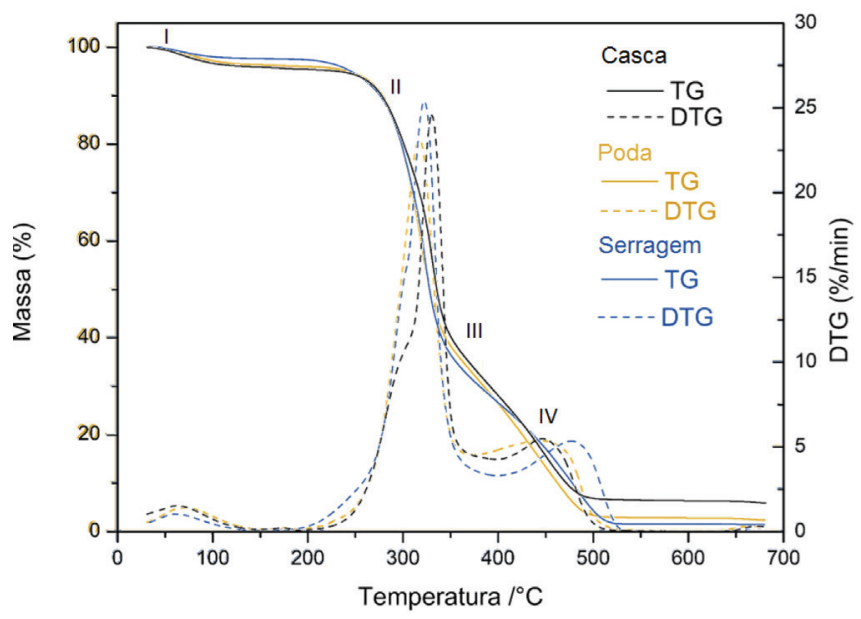

Figura 1. Curva Termogravimétrica (TG) e Derivada da Curva Termogravimétrica (DTG) em função da temperatura para Casca de eucalipto, Poda urbana e Serragem de eucalipto

A análise termogravimétrica (TGA) é uma método rápido e eficiente e tem sido utilizado de forma ampla no estudo das propriedades físicas e químicas de materiais sólidos. Utiliza uma pequena quantidade de amostra $(\mathrm{mg})$, além da redução de tempo (30-60 min) comparado com a análise imediata (6-10 h). ${ }^{48,49}$ Analisa a decomposição térmica do material, ou seja, as alterações no peso em função da temperatura com taxa de aquecimento e atmosfera controladas. ${ }^{49}$ Os perfis TGA e DTG obtidos podem ser utilizados para determinar o comportamento da combustão e as temperaturas características da combustão de cada componente da biomassa (hemicelulose, celulose e lignina). Isso possibilita identificar as temperaturas de ignição, pico e estabilização da decomposição do material, bem como o tempo de queima numa caldeira. ${ }^{49}$

Na Figura 1, observa-se que o evento I tem o mesmo comportamento para os três materiais. O evento I compreende temperaturas inferiores a $100^{\circ} \mathrm{C}$, evidencia uma pequena diminuição de massa atribuída à evaporação. Os eventos II e III envolvem a degradação da holocelulose (hemiceluloses e celulose). No evento II, o pico da curva de DTG corresponde a taxa máxima de perda de peso $^{49}$ e está associado onde ocorre a maior degradação da celulose. ${ }^{50}$ O evento teve início em torno de $200^{\circ} \mathrm{C}$ (serragem) e $215^{\circ} \mathrm{C}$ (poda e casca) e se estendeu até cerca de $400^{\circ} \mathrm{C}$. Nos eventos II e III ocorreu a maior perda de massa (em torno de $80 \%$ ). O evento IV $\left(400-500{ }^{\circ} \mathrm{C}\right.$ ) está associado aos processos de degradação e quebra das estruturas das cadeias moleculares da lignina..$^{51}$ Temperaturas em torno de $500{ }^{\circ} \mathrm{C}$ associa-se à decomposição de anéis aromáticos. ${ }^{51}$ No estágio final da degradação, temos a temperatura de burnout, que é a temperatura onde não há mais perda de massa, ${ }^{49}$ restando apenas massa de cinzas. No estudo, a temperatura de burnout foi atingida acima de $500{ }^{\circ} \mathrm{C}$. Observa-se que a massa restante da queima é superior em casca (próxima a $10 \%$ ), seguida de poda urbana (3\%) e serragem $(1 \%)$, resultados compatíveis aos encontrados na análise imediata.

\section{Ensaios mecânicos}

A Figura 2 apresenta o gráfico de expansão volumétrica dos briquetes das medições realizadas ao longo de 48 horas.

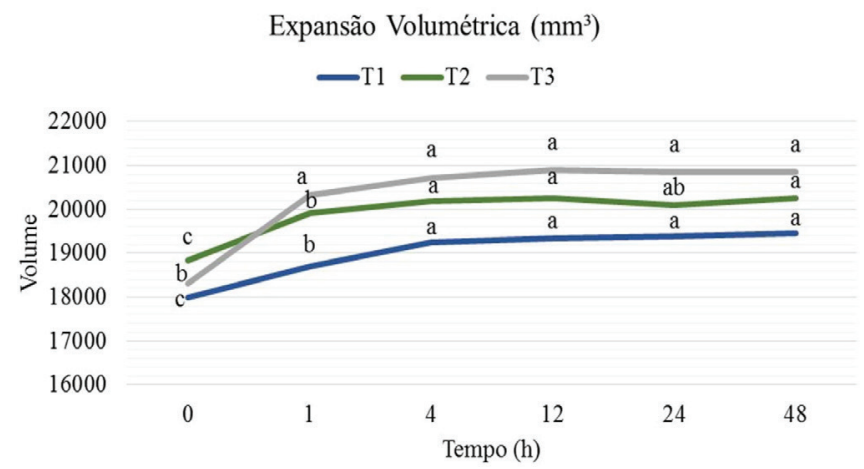

Figura 2. Expansão volumétrica dos briquetes: T1 (100\% casca); T2 (50\% casca $+50 \%$ poda $) ;$ T3 $(50 \%$ casca $+25 \%$ poda $+25 \%$ serragem $)$. Letras iguais na mesma curva não diferem significativamente para teste de Tukey

As curvas da Figura 2 mostram que a expansão volumétrica ocorreu nas quatro primeiras horas. Para todos os tratamentos os briquetes apresentaram uma estabilidade dimensional $4 \mathrm{~h}$ após a prensagem.

A Tabela 3 apresenta os valores médios finais de expansão longitudinal, diametral e volumétrica, 48 h após briquetagem dos tratamentos T1, T2 e T3.

Na medição final, os tratamentos T1, T2 e T3 apresentaram respectivamente expansão volumétrica média de 8,46\%,7,40\% e $9,68 \%$, em relação aos volumes iniciais. Estatisticamente, T3 registrou as maiores expansões longitudinal e volumétrica, indicando instabilidade dimensional dos briquetes. Segunda Silva et al.,${ }^{26}$ após a prensagem há uma tendência de expansão nos briquetes, que varia em função do tipo de biomassa, granulometria, umidade e condições do ambiente de armazenamento. Nesse estudo, o acondicionamento dos briquetes foi realizado em condições de temperatura e umidade relativa próximas ao ambiente da indústria.

Uma forma de controlar a expansão é com o uso de aglutinantes na produção dos briquetes. Entretanto, aplicação de aglutinantes significa mudanças no processo e aumento nos custos de produção. A expansão dos briquetes é indesejável, pois vai interferir negativamente nas propriedades mecânicas. Os briquetes com maior expansão (menor estabilidade dimensional) apresentarão menor resistência mecânica. ${ }^{19}$

A Tabela 4 apresenta os resultados dos ensaios mecânicos: resistência máxima, módulo elástico e resiliência; realizados para os tratamentos de briquetes T1, T2 e T3. 
Tabela 3. Expansões Finais (\%) dos tratamentos de briquetes, em relação às medições realizadas 48 h após briquetagem

\begin{tabular}{cccc}
\hline Expansão Final (\%) & T1 & T2 & T3 \\
\hline Longitudinal & $6,46 \pm 0,97 \mathrm{~b}$ & $6,44 \pm 1,16 \mathrm{~b}$ & $8,02 \pm 0,52 \mathrm{a}$ \\
Diametral & $0,93 \pm 0,33 \mathrm{a}$ & $0,58 \pm 0,39 \mathrm{~b}$ & $0,81 \pm 0,15 \mathrm{ab}$ \\
Volumétrica & $8,46 \pm 1,41 \mathrm{ab}$ & $7,40 \pm 1,63 \mathrm{~b}$ & $9,68 \pm 0,71 \mathrm{a}$ \\
\hline
\end{tabular}

${ }^{\mathrm{a} O s}$ valores da tabela 3 representam as médias dos tratamento \pm desvio padrão. Letras iguais na mesma linha não diferem significativamente para teste de Tukey.

Tabela 4. Resistência máxima, módulo elástico e resiliência para os tratamentos de briquetes

\begin{tabular}{cccc}
\hline Tratamentos & T1 & T2 & T3 \\
\hline Resistência Máxima (MPa) & $1,095 \pm 0,098 \mathrm{a}$ & $0,738 \pm 0,033 \mathrm{~b}$ & $0,630 \pm 0,052 \mathrm{c}$ \\
Módulo Elástico (MPa) & $48,10 \pm 4,15 \mathrm{a}$ & $34,18 \pm 1,67 \mathrm{~b}$ & $26,89 \pm 1,93 \mathrm{c}$ \\
Resiliência (\%) & $92,36 \pm 1,82 \mathrm{a}$ & $94,49 \pm 4,67 \mathrm{a}$ & $63,29 \pm 2,11 \mathrm{~b}$ \\
\hline
\end{tabular}

${ }^{a}$ Os valores da tabela representam as médias dos tratamento \pm desvio padrão. Letras iguais na mesma linha não diferem significativamente para teste de Tukey.

O tratamento T1, estatisticamente, obteve as maiores médias nos ensaios mecânicos, sendo: Resistência Máxima (1,095 MPa); Módulo Elástico (48,097 MPa) e Resiliência (92,36\%). Os valores de resistência máxima de T1 (100\% casca) foram próximos aos valores encontrados para briquetes de serragem de eucalipto - 1,215 Mpa. ${ }^{36}$ Os valores T2 (50\% casca $+50 \%$ poda) e T3 (50\% casca, $25 \%$ poda urbana e $25 \%$ serragem de eucalipto) aproximaram-se dos resultados obtidos para briquetes produzidos com poda de jardim $(0,79 \mathrm{MPa}){ }^{19}$ Segundo Silva et al.,${ }^{26}$ normalmente atribui-se que briquetes com maior estabilidade dimensional (menor expansão dimensional) possuem maior resistência mecânica. Briquetes com valores de expansão dimensional acima de $20 \%$ comprometem a resistência mecânica. Os briquetes com maior estabilidade dimensional (menor expansão longitudinal) foram T1 $(6,46 \%)$ e T2 $(6,44 \%)$, e que apresentaram a maior resistência mecânica (tamboramento) com uma resiliência de T1 $(92,36 \%)$ e T2 $(94,49 \%)$. Ainda, de acordo com Silva et al. ${ }^{26}$ briquetes com resistência máxima $>0,27 \mathrm{MPa}$ podem ser considerados com resistência mecânica aceitável.

\section{CONCLUSÕES}

- A serragem (resíduo da produção dos painéis) foi o material que apresentou as melhores características para uso como combustível.

- Os resíduos da poda urbana apresentaram características que possibilitam o seu uso em caldeiras de biomassa, apesar da heterogeneidade.

- A casca de eucalipto foi o material que apresentou o pior desempenho (umidade elevada e alto teor de cinzas). Contudo, devido à disponibilidade (grande volume gerado) é um material que precisa ser utilizado.

- A produção de briquetes pode ser uma alternativa para o aproveitamento dos resíduos e melhorar a qualidade dos combustíveis sólidos.

- Os briquetes T1 (100\% casca) apresentaram a maior resistência mecânica. No entanto, deve-se buscar a formação de blendas para minimizar o teor de cinzas na caldeira. Assim, blendas T2 e T3 podem ser consideradas como as melhores alternativas para a empresa.

\section{AGRADECIMENTOS}

O presente trabalho foi realizado com apoio da Coordenação de Aperfeiçoamento de Pessoal de Nível Superior - Brasil (CAPES) - Código de Financiamento 001, Conselho Nacional de
Desenvolvimento Científico e Tecnológico (CNPq) e Grupo de Pesquisa Biomassa Bioenergia.

\section{REFERÊNCIAS}

1. Kang, S.; Selosse, S.; Maïzi, N.; Biomass Bioenergy 2018, 111, 142.

2. Bilgili, F.; Ozturk, I.; Renewable Sustainable Energy Rev. 2015, 49, 132.

3. Ghani, N. M. A.; Vogiatzis, C.; Szmerekovsky, J.; Energy Policy 2018 , 116, 39.

4. Lee, D.; Int. J. Hydrogen Energy 2017, 42, 27701.

5. Suopajärvi, H.; Kemppainen, A.; Haapakangas, J.; Fabritius, T.; J. Cleaner Prod. 2017, 148, 709.

6. Burhenne, L.; Messmer, J.; Aicher, T.; Laborie, M..; J. Anal. Appl. Pyrolysis 2013, 101, 177.

7. Denari, G. B.; Cavalheiro, E. T. G; Contribuições ao ensino de análise térmica: desenvolvimento histórico e experimentos, Instituto de Química de São Carlos: São Carlos, 2016.

8. Garcia-Maraver, A.; Mata-Sanchez, J.; Carpio, M.; Perez-Jimenez, J. A.; J. Energy Inst. 2017, 90, 214.

9. Castillo-Villar, K. K.; Eksioglu, S.; Taherkhorsandia, M.; J. Cleaner Prod. 2017, 149, 904.

10. Sette, C. R.; de Moraes, M. D. A.; Coneglian, A.; Ribeiro, R. M.; Hansted, A. L. S.; Yamaji, F. M.; Waste Manage. 2020, 114, 196.

11. Lisowski, A.; Wójcik, J.; Klonowski, J.; Sypuła, M.; Chlebowski, J.; Kostyra, K.; Nowakowski, T.; Strużyk, A.; Świętochowski, A.; Dąbrowska, M.; Mieszkalski, L.; Piątek, M.; Biomass Bioenergy 2020, 139, 105631.

12. Nakashima, G. T.; Martins, M. P.; Silva, D. A.; Chrisostomo, W.; Yamaji, F. M.; Revista Brasileira de Ciências Ambientais 2014, 34, 22.

13. ASTM E871-82 Standard; ASTM International 2013.

14. Konishi, P. A.; Hansted, A. L. S.; Gabriela, N. T.; Padilla, E. R. D.; da Róz, A. L.; Sette Jr, C. R.; Yamaji, F. M.; Rev. Virtual Quim. 2017, 9 , 1065.

15. Hansted, A. L. S.; Nakashima, G. T.; Martins, M. P.; Yamaji, F. M.; Rev. Virtual Quim. 2016, 8, 1449.

16. TAPPI T $264 \mathrm{~cm}-97$, Preparation of wood for chemical analysis, TAPPI, 1997.

17. Nakashima, G. T.; Adhman, I. C. S.; Hansted, A. L. S.; Belini, G. B.; Waldman, W. R.; Yamaji, F. M.; Rev. Virtual Quim. 2017, 9, 150.

18. TAPPI T $204 \mathrm{~cm}-97$, Solvent extractives of wood and pulp, TAPPI, 1997.

19. TAPPI T 222 om-02, Acid-insoluble lignin in wood and pulp, TAPPI, 2002.

20. Parshetti, G. K.; Fuel Process. Technol. 2014, 118, 228.

21. El-Sayed, S. A.; Mostafa, M. E.; Energy Convers. Manage. 2014, 85, 165. 
22. Ergudenler, A.; Ghaly, E.; Appl. Biochem. Biotechnol. 1992, 34, 75.

23. Gonçalves, B. F.; Yamaji, F. M.; Fernandez, B. O.; Róz, A.; Floriano, F. S.; Revista do Instituto Florestal 2013, 45, 713.

24. Amaral, P. M.; Yamaji, F. M.; Oliveira, P. B. M. de; Silva, D. A. da; Silva, J. M. S. da; Guerra, S. P. S.; Revista do Instituto Florestal 2015, 27,73 .

25. ABNT.; ABNT NBR 72222011.

26. Silva, D. A.; Nakashima, G. T.; Barros, J. L.; da Róz, A. L.; Yamaji, F. M.; Floresta 2015, 45, 4.

27. R Development Core Team; $R$ Core Team; R Foundation for Statistical Computing: Austria, 2017.

28. Foelkel, C.; Eucalyptus Online Book \& Newsletter, Esalq: Piracicaba, 2016.

29. Demirbas, A.; Sahin-Demirbas, A.; Energy Sources 2004, 26, 83.

30. Hossain, N.; Jalil, R.; Mahlia, T. M. I.; Zaini, J.; International Journal of Technology 2017, 8, 634.

31. Silva, D. A.; da Róz, A. L.; Pires, A. A. F.; de Carvalho, A. M.; Nakashima, G. T.; de Pádua, F. A.; Yamaji, F. M.; Rev. Virtual Quim. 2017, 9, 1078 .

32. Dias, J. M. C. de S.; Santos, D. T. dos; Braga, M.; Onoyama, M. M.; Miranda, C. H. B.; Barbosa, P. F. D.; Rocha, J. D.; Produção de briquetes e peletes a partir de resíduos agrícolas, agroindustriais e florestais, Embrapa Agroenergia: Brasília, 2012.

33. Juizo, C. G. F.; Lima, M. R.; Silva, D. A.; Agrária 2017, 12, 386.

34. Mande, S. P. Em Thermo chemical conversion of biomass; Kishore, V. V. N., eds.; The Energy and Resources Institute: New Delhi, 2009.

35. Neiva, D. M.; Araújo, S., Gominho, J., Carneiro, A., de, C., Pereira, H.; Ind. Crops Prod. 2018, 123, 262.

36. Tomeleri, J. O. P.; Valentim, L. B.; da Silva, J. P.; de Pádua, F. A.; Yamaji, F. M.; Rev. Virtual Quim. 2017, 9, 942.
37. Sette Jr, C. R.; Hansted, A.L.S.; Novaes, E.; Lima, P.A.F.E.; Rodrigues, A.C.; Santos, D.R.S.; Yamaji, F. M.; Ind. Crops Prod. 2018, 122, 209.

38. Lu, Z.; Chen, X.; Yao, S.; Qin, H.; Zhang, L.; Yao, X.; Yu, Z.; Lu, J.; Fuel 2019, 258, 116150.

39. Yu, D.; Chen, M.; Wei, Y.; Niu, S.; Xue, F.; Powder Technol. 2016, 294, 463.

40. Motghare, K. A., Rathod, A. P.; Wasewar, K. L.; Labhsetwar, N. K.; Waste Manage. 2016, 47, 40.

41. http://faostat.fao.org/site/626/DesktopDefault.aspx?PageID=626\#, acessada em Outubro 2019.

42. Teixeira, C. M.; Martins, M. P.; Yamamoto, H.; Chrisostomo, W.; Yamaji, F. M.; Rev. Virtual Quim. 2016, 8, 1693.

43. Moulin, J. C.; Arantes, M. D. C.; Vidaurre, G. B.; Paes, J. B.; Carneiro, A. C. O.; Rev. Arvore 2015, 39, 199.

44. Xiao, M.-Z.; Int. J. Biol. Macromol. 2019, 138, 519.

45. Morais, A.P. S.; Sansígolo, C. A.; Neto, M. O.; Bioresour. Technol. 2016, 214, 623.

46. González, Z.; Rosal, A.; Requejo, A.; Rodríguez, A.; Bioresour. Technol. 2011, 102, 9330 .

47. Ferreira, G. W. D.; Roque, J. V.; Soares, E. M. B.; Silva, I. R.; Silva, E. F.; Vasconcelos, A. A.; Teófilo, R. F.; Talanta 2018, 188, 168.

48. Guo, F.; He, Y.; Hassanpour, A.; Gardy, J.; Zhong, Z.; Energy 2020, 197 , 117147.

49. Idris, S. S.; Rahman, N. Abd; Ismail, K.; Bioresour. Technol. 2012, 123, 581.

50. Skeireberg, A.; Skreiberg, A.; Skreiberg, Ø.; Sandquist, J.; Sørum, L.; Fuel 2011, 90, 2182.

51. Waltkins, D.; Nuruddin, M.; Hosur, M.; Tcherbi-Narteh, A.; Jeelani, S.; J. Mater. Res. Technol. 2015, 23, 1 . 